\title{
IMAPBOOK: ENGAGING YOUNG READERS WITH GAMES ${ }^{1}$
}

\author{
The research clearly shows that students enjoy and learn from reading the books we have created \\ incorporating interactive games. The question is how to bring the technology to market.
}

Glenn Smith, Associate Professor in the College of Education at the University of South Florida (USF), pondered the challenge presented by the need to transform his research into a marketable product. For more than two years he had worked with doctoral students and his wife, Mieke Caris, to develop a platform for embedding games into online books. Classroom testing in the Netherlands and elsewhere had demonstrated the efficacy of the approach. The next step required was commercialization, without which the benefits of using the technology could not be realized on a broader scale.

The platform, referred to as IMapbook, was a web-based technology that allowed reading material to be intermingled with interactive games that were intended to boost student comprehension and to keep students engaged with the material for longer periods of time. While most of the interactive component resided on the user's browser, the system also included a modest server side back end that both delivered the content to the user and allowed a wide range of student performance data to be collected for later analysis, both by the student's instructor and, potentially, by researchers. The principal developer of the technology, Jack Drobisz, also collaborated with Smith on the research aspects of the tool.

In 2011, Smith and Caris formed a limited liability company (LLC) to commercialize the technology. Later, Drobisz had joined the company. Although the original focus of the technology had been on struggling readers, the group came to realize that, from a practical perspective, the best initial market would be home school students. Unlike school districts, these students (or, more precisely, their parents) had considerable flexibility in their choice of materials and were used to working independently. Even with this target market in mind, however, many questions remained unanswered. What business model would make the most sense: subscription, selling individual books, renting books for a specified period or some hybrid model, perhaps even a joint venture with a publisher? How should appropriate content (books) be selected, and how could more books be added quickly? How critical to the venture's success was the tool for authoring books, and how should it be designed?

More broadly, the issue of how the research objectives of the project could co-exist with its commercial ambitions had surfaced. This concern had become more pressing because USF's licensing arm had started to inquire, politely at first, as to when they might expect to see fee revenue from the patent.

\footnotetext{
${ }^{1}$ Copyright $($ 2013, Informing Science Institute. This case was prepared for the purpose of class discussion, and not to illustrate the effective or ineffective handling of an administrative situation. Names and some information have been disguised. Permission is granted to copy and distribute this case for non-commercial purposes, in both printed and electronic formats.
} 


\section{Home Schooling in the U.S.}

A market of particular interest to Smith and Caris was the U.S. home school students. A U.S. Government "Fast Facts" website based on a 2009 report by the U.S. Department of Education, National Center for Education Statistics summarized the home schooled market as follows:

In 2007, the number of homeschooled students was about 1.5 million, an increase from 850,000 in 1999 and 1.1 million in 2003. The percentage of the school-age population that was homeschooled increased from 1.7 percent in 1999 to 2.9 percent in 2007. The increase in the percentage of homeschooled students from 1999 to 2007 represents a 74 percent relative increase over the 8-year period and a 36 percent relative increase since 2003. In 2007, the majority of homeschooled students received all of their education at home (84 percent), but some attended school up to 25 hours per week. Eleven percent of homeschooled students were enrolled in school less than 9 hours per week, and 5 percent were enrolled between 9 and 25 hours per week.

More White students were homeschooled than Black or Hispanic students or students from other racial/ethnic groups, and White students constituted the majority of homeschooled students (77 percent). White students ( 3.9 percent) had a higher homeschooling rate than Blacks ( 0.8 percent) and Hispanics (1.5 percent), but were not measurably different from students from other racial/ethnic groups (3.4 percent). Students in two-parent households made up 89 percent of the homeschooled population, and those in two-parent households with one parent in the labor force made up 54 percent of the homeschooled population. The latter group of students had a higher homeschooling rate than their peers: 7 percent, compared with 1 to 2 percent of students in other family circumstances. In 2007, students in households earning between $\$ 25,001$ and $\$ 75,000$ per year had higher rates of homeschooling than their peers from families earning $\$ 25,000$ or less a year.

Parents give many different reasons for homeschooling their children. In 2007, the most common reason parents gave as the most important was a desire to provide religious or moral instruction (36 percent of students). This reason was followed by a concern about the school environment (such as safety, drugs, or negative peer pressure) (21 percent), dissatisfaction with academic instruction (17 percent), and "other reasons" including family time, finances, travel, and distance (14 percent). Parents of about 7 percent of homeschooled students cited the desire to provide their child with a nontraditional approach to education as the most important reason for homeschooling, and the parents of another 6 percent of students cited a child's health problems or special needs.

(Source: $\underline{\text { http://nces.ed.gov/fastfacts/display.asp?id=91) }}$

The home school market channel offered a number of advantages over the substantially larger public school market. Among these:

- Making book sales to public schools was a time consuming, expensive, and highly competitive proposition. Textbook selection was typically made at the district or even state level (e.g., in Texas). Aside from major publishing houses, there was little opportunity for new market entrants.

- Many existing public schools lacked the computer hardware (e.g., PCs, laptops, or even tablets) necessary to run an interactive product such as iMapBooks.

- Particularly in economically disadvantaged locations, parental involvement in their children's' education (and accompanying willingness to acquire supplemental materials) was often low. 
In contrast, according to 2009 study of 11,739 participants commissioned by the Home School Legal Defense Association (Source: http://www.hslda.org/docs/study/ray2009/2009_Ray_StudyFINAL.pdf):

- Almost all home-schooled students (98.3\%) used a computer at home.

- Parental involvement in home schooling was necessarily high, and parents were the key decision makers in acquiring educational materials.

- Average achievement of home-schooled students - as measured by standardized tests - was substantially higher than for public schools students. Home schooled students scored 34-39\% percentile points higher, on average, than public school students.

- The market was growing rapidly, nearly doubling in the decade between 1997 and 2007.

The study also highlighted a number of challenges facing any potential entrant to the market. Among these:

- The median amount of money spent for each home-schooled child per year was in the \$400-599 range, as contrasted with a nearly $\$ 10,000 /$ student average for public education. Such a small annual budget suggested an unwillingness to spend large amounts of money on single study aid.

- Home schooled families generally had a strong religious motivation for their choice (see Exhibit 1), a percentage that might even be increasing. That could significantly impact the nature of materials desired.

- Without a centralized purchasing entity, such as a school district, a significant marketing effort would likely be required to expand sales.

Despite these challenges, the engaging nature of iMapBooks meant that they would be a particularly good fit with settings in which students were reading independently of classroom supervision. Thus, the home school market seemed the logical first choice.

\section{eBook Technologies}

The iMapBook system would be an entrant in a rapidly growing eBook marketplace. Although maturing rapidly, there nonetheless remained many different technologies through which eBook contentincluding interactions - could be delivered. These technologies included applications that:

- ran on the user's device

- ran on a centralized server

- allowed authors to create content

Each of these had practical relevance to iMapBooks.

\section{eBook Reader Technologies}

Whatever the format an eBook is delivered in, in order to read it on a particular device, an appropriate reader application must be installed. These applications can be classified in two broad categories: general purpose and dedicated eReader devices and software.

\section{General purpose reading solutions}

General purpose applications can be used for a variety of functions of which reading is only one. Many common software applications fit into this category. These include:

- Text and graphic editing applications, such as word processors (e.g., MS-Word) and presentation software (e.g., PowerPoint). These applications were typically focused on content creation and 
editing rather than reading, but could be used for both. Their principal weaknesses included the cost of acquiring them. Their intrinsic flexibility also made it difficult to define the reader's experience. They also tended to be most effective when the device used to create them was of a similar form factor to the reader's device - e.g., a PowerPoint created for a PC would often be hard to read on a cell phone and might not support all the editor's features.

- Content display applications, such as Adobe Reader and various viewer technologies available for MS-Office. These applications removed the editing capabilities of the previous category, thereby making it easier to define the reader's experience and also tended to be free or low cost. Additionally, some of these supported embedded animations and allowed interactions with the user (e.g., responses to button presses) to be incorporated. Like the editors, however, these applications could be problematic when moved between different form factors and often lacked the ability to adjust to a reader's needs (such as visually impaired users who required a larger font).

- Animation applications. Often embedded within other technologies (e.g., Acrobat PDF files, web pages), these technologies - such as Adobe's Flash - allowed for a highly interactive user experience, supported by text, images, and animated graphics. The category presented two major challenges, however. First, content creation was quite complex (see section on Creating Content), being a type of programming that also depended heavily upon the author's intrinsic design sense. Second, support across different device platforms was inconsistent or non-existent. For example, Apple chose not to support Flash on its iPhone or iPad devices and Google chose to abandon such support for later versions of its Android operating system.

- Web browsers: Web browsers, which displayed pages written in the hypertext markup language (HTML), were the most ubiquitous reader application, being available on nearly every device. Web pages generally offered greater adaptability to user special needs than the typical word processing document, and interactivity with the user could be supported through the use of JavaScript. Historically, embedding animations had relied heavily on $3^{\text {rd }}$ party applications (such as Flash). That was changing, however, with the introduction of a new HTML 5 standard that introduced the ability to define a graphic canvas within the HTML document. Although support for the new standard was growing rapidly, variations across browsers persisted and there remained the problem of inconsistency across different device form factors.

One problem that was common to nearly all the general-purpose reader technologies was the difficulty in enforcing copyrights for the content distributed to users - unlike paper-based books, electronic media was easily copied. As more and more reading material went online, the issue of digital rights management grew in importance.

\section{Dedicated eReader devices and software}

In 2004, Sony introduced what might be described as the first modern commercial eReader, the LIBRIé. It was a commercial failure, but paved the way for the most successful eReader product, Amazon's Kindle, in 2007. By 2011, Amazon - the world's largest bookseller of any kind - reported that its Kindle sales had actually exceeded its physical book sales.

The rapid growth of eBooks could be attributed to a variety of factors: 1) the price of eBooks was generally less than hardcover counterparts, although the difference between the two had been declining, 2) although eBooks were marketed for a particular device, software that emulated the device was widely available on other platforms - meaning that a Kindle book could be read on a PC, an iPad, or even an Android phone, and 3) content distribution channels (e.g., Amazon's Kindle store, Apple's iTunes) made acquiring the books both rapid and easy. 
Software that emulated eReader devices, such as the Kindle, came in a variety of forms. Most commonly, it was supplied as a stand-alone application. Sometimes, however, it was provided as a plug in to a web browser or other application (such as a word processor). These hybrids blurred the distinction between dedicated and general purpose eReaders.

Dedicated eReader devices and software tended to differ from their general purpose counterparts in the quality of the reading experience they offered. Specifically, the dedicated eReader made it easy to change fonts, keep track of where reading left off, and jump between different locations in the table of contents. They also provided support for digital rights management, making it far more difficult to give away free copies of a book. They provided tools analogous to those used by traditional readers, such as the ability to highlight text passages and add notes to the margins. Being able to connect to the Internet, they also allowed these user-annotations to be shared across devices and even between different readers of the same book. In fact, Amazon's Whispersync technology even allowed the reader to switch back and forth between Kindle books and audio books without losing his or her place.

Although dedicated eReader technologies tended to provide an excellent user experience, they were less flexible than their general-purpose counterparts in their ability to incorporate animations and other authordefined interactions. If these needed to be incorporated into the reading experience, an alternative was to create an "app" for a specific category of device (e.g., iPhone/iPad or Android). While such apps could be distributed through the same channels as eBooks, going the app route generally meant losing many of the desirable features supported by eReaders.

\section{eBook Server-Side Technologies}

Although reading a book was normally an individual activity, eBooks - particularly those read on dedicated devices and software - typically relied heavily on cloud-based servers. These servers provided three important functions:

- They supported the purchase and delivery of eBook content

- They maintained the data necessary to allow readers to move seamlessly between connected devices and to share information (e.g., highlights, comments) between users

- They checked that digital rights were not being violated.

Because these functions were not strictly required in order to read a book that had already been purchased and downloaded, it was possible to read eBooks when not connected to the Internet.

For the general purpose technologies used for reading, the situation was somewhat less well defined. Browser-based approaches normally relied on the availability of a continuous web connection throughout the reading process. Other general purpose documents (e.g., PDF files) were more readily downloaded and viewed independently. Whenever information needed to be shared across devices, for example if a parent wanted to monitor a child's reading progress, some type of server-side application normally likely be required.

\section{eBook Content Creation}

Broadly speaking, dedicated eBooks employed formats based on HTML and/or the extensible markup language (XML), which had become a nearly universal standard for exchanging data. Different readers employed different formats, however. For example, Kindle's supported a format based on the Mobi standard, whereas Apple relied on the EPUB standard. While these standards were not directly compatible, a variety of applications were available that could make conversions between different formats. 
Many different applications could be used to author eBooks. Professional publishing applications, such as Adobe's InDesign, provided the greatest flexibility in features and formatting, although they were expensive as well as being complicated to learn and use. Other applications were cheaper, easier to use and much more limited in their feature set. An example of this was iBooks Author, a free application for authoring eBooks for the iPad. Another approach was to employ a plug-in to a standard word processor, such as Aspose Word Express, that could then be used to save a document into an eBook format. It was also possible to write the XML/HTML code for an eBook directly using a plain text editor. This provided the greatest flexibility, but placed the largest demands on the author, since doing so meant working outside the more user-friendly "what you see is what you get" (WYSIWYG) environment of a publishing application.

The greater the degree to which an eBook incorporated complex user interactions, the greater the likelihood that the author would need to move beyond standard authoring systems and work more directly with the underlying code and, possibly, develop a special purpose reader. While existing formats - such as the KF8 format introduced for Amazon's Kindle Fire line of tablet devices - directly supported greater interactivity, such formats were device dependent and authoring tools had yet to be developed that allowed the author to take advantage of the features easily. The general purpose browser-based eReader was more flexible in this regard. Using the browser's built in Javascript engine, the eBook's XML could be converted into text and instructions for interactions that could be defined by the author. This approach, the one employed in the prototype version of iMapBooks, provided nearly limitless flexibility and the promise of widespread support across devices. It greatly magnified the authoring challenge, however, since it meant that creating interactions - particularly new interactions - demanded considerable programming skill.

\section{Background of IMapBooks}

The IMapBook (short for Interactive Map Book) was an eBook in which the chapters were re-ordered in a seeming random order so that the reader did not read the book sequentially. Instead, each chapter of the book ended in a computer game. The reader needed to win the game to discover the next page number from which to read (patent pending). The computer games were implemented with pentop computers providing audio feedback when the pen was touched to specific places on paper, in particular situations. The genesis of IMapBooks is described in Exhibit 2.

Dr. Smith obtained a small grant from University of South Florida that paid for a couple of students to work on the project for a year. However, the great bulk of the work done on the IMapBook project was done by graduate students for credit taking a course that Dr. Smith created called Prototype Game Research. The students in Prototype Game Research created at least 20 prototype books and conducted numerous research studies. Dr. Smith, with the help of students in Prototype Game Research, persuaded the Patents and Licensing Department at University of South Florida to apply for a U.S. Patent for IMapBooks.

Since the pentop computer technology had apparently not found its "killer app" and was not taking off in popularity, in the Spring of 2011, Dr. Smith decided to implement a Web-based version of IMapBook. By the end of summer 2011, one of Dr. Smith's PhD students, Jack Drobisz, had implemented a prototype web-based eReader for iMapBooks. With the web-based IMapBook model, it was no longer necessary to re-order chapters in a "random" manner, since access to the next chapter after a game could easily be controlled and constrained.

With the web-based version of IMapBooks in place, events accelerated. Dr. Smith initiated a new type of game for IMapBooks, which addressed the cognitive process of inferencing, also fundamental to narrative text comprehension, i.e., taking two or more pieces of information and combining them with reader's life 
knowledge to fill in gaps in the text. Dr. Smith and his wife, Mieke Caris, founded IMapBook LLC. Dr. Smith collaborated with reading researchers at Leiden University in the Netherlands, to conduct an experiment in 25 schools with sixth graders. The IMapBook group wrote and created the games for a fulllength science fiction novel, with solar system science content, for sixth graders called Weightless. They conducted a series of formative evaluations, on both the science fiction novel and the eReader interface. IMapBook LLC added another partner, Jack Drobisz, as the architect and main director of software. Dr. Smith persuaded the partners that they should adopt the iterative startup model described in the book, The Lean Startup by Eric Ries, which advocated releasing products (with a minimal set of features) as soon as they were commercially viable and then enhancing them incrementally in response to market needs.

\section{Description of IMapBook Software}

IMapBooks were web-based eBooks with embedded computer games intended to (a) motivate middle school students to read, (b) promote and stealth-assess comprehension and learning of content and provide ongoing authentic, formative assessment, (c) adapt eBooks to student reading levels, (d) allow teachers to monitor student progress, set up cohorts with custom bookcases, and (e) let middle school students author their own eBooks with computer games. IMapBooks were designed to be self-sufficient courseware for reading/writing literacy, including bookcases of eBooks with game-based assessments, teacher \& student tutorials, and lesson plans. IMapBooks let kids read, play, and create.

IMapBooks were delivered as web-based eBooks, where chapters of text alternated with computer games. Students needed to comprehend the preceding text to win the games and needed to win the games to advance to the next chapter of text (patent pending). The design of the games in IMapBooks was based on important cognitive processes skilled readers use to comprehend text. For example, many games in IMapBooks were based on inferencing, the cognitive process that readers use to fill gaps when they infer information from other information presented in the story.

IMapBooks were also designed to allow students and teacher to create and publish their own web-based eBooks with embedded computer games. IMapBooks used game interaction to let students visualize a book. As a sixth grader in one of our studies remarked, "I map the book." A series of screen captures from an actual IMapBook are presented in Exhibit 3. Results of research on the effectiveness of IMapBooks are summarized in Exhibit 4.

\section{Current Situation}

With a prototype product that was largely functional, Smith found himself looking to the future. There remained numerous decisions that needed to be made if the product was to achieve its full potential. He organized these decisions into broad categories. Specifically:

- Making the product content more engaging and easier to develop

- Defining the company's business model

- Establishing communities of readers and content developers

- Acquiring external capital

More broadly, greater clarity was needed as to where the product's research objectives ended and commercial objectives began. This decision had become particularly urgent because his employer, the University of South Florida, was currently underwriting the expenses associated with acquiring a U.S. patent on the system and was pressing Smith to begin paying licensing fees. 


\section{Enhancing Product Features and Content Development}

Drawing upon the concepts presented in The Lean Startup, Smith and Drobisz had created the reader with a limited number of types of interactions ( 6 in all) and had developed the authoring tool using the same technology (JavaScript) as the game engine. In order to move forward, a series of questions had arisen related to what constituted the "minimum" feature set for successful commercialization and whether or not the existing architecture would meet the IMapBook's near term and longer term needs.

With respect to the interactions, feedback from sixth graders had already suggested a desire for elements that were more game-like, as opposed to being puzzles. While such interactions could certainly be designed, each one would take significant effort—as both the engine for the book itself and the designer for authoring the application would need to be developed. The need for more interaction categories was also likely to depend upon the type of books the company focused on. For short stories, existing elements might be sufficient; for longer stories or novels, having a limited number of interaction categories would likely require that the same interaction be used many times. To the reader, that might seem repetitive, leading to loss of engagement.

The issue of finding the right set of interactions was closely related to the authoring system architect. The current version of IMapBooks used a browser-based authoring system that employed JavaScript. It was efficient for experienced users who were familiar with the XML structure used by the product, but was not particularly user-friendly to new developers.

A major advantage of the current approach was that development and reading used the same platform. This meant that there would be few technological obstacles to a significant long term objective for the product: allowing young readers to develop their own books and games (using pre-defined interactions). A disadvantage of this approach was the fact that JavaScript had never been conceived as an environment for full-scale application development and lacked the sophisticated array of development tools associated with technologies such as Microsoft's .NET and Java. This could limit the range of more advanced activities that could be created.

An alternative approach would be to migrate the authoring tool to a more advanced development environment (e.g., Java), while keeping the reader JavaScript-based. Because interactions themselves were defined in XML (a text-based representation), this approach would present no insurmountable technological obstacles. It would, however, involve discarding a great deal of the current authoring code and rewriting it. It could also introduce platform dependence to the authoring tool. This could, perhaps, prevent some users - who had incompatible systems - from creating their own books and games, even though they could still read the browser-based books.

The greatest advantage of developing books in a separate application from the reader would be the ease with which an intuitive graphic user interface (GUI) for developing books could be implemented. In addition, the facilities provided by advanced development tools might make it possible for $3^{\text {rd }}$ party programmers to create components that could be added to the development tool to support authoring and delivering new interactions.

An even more radical redesign could involve re-thinking the form in which an IMapBook was delivered. Although the browsers available (at the time of the case) supported significantly more interactive capabilities than common eBook formats, they situation was changing rapidly. Within a few years, it was likely that many new and upgraded eBook formats would be introduced that provided broad support for HTML 5 and JavaScript (the core technologies required by the IMapBooks engine). As these formats became available, it would open new potential distribution channels-such as iTunes and Amazon's Kindle store. Even this would be a mixed blessing, however, as many individuals read books on devices such as 
smartphones, and this form factor would not be well suited to the existing set of IMapBook interactions. In addition, the evaluation component of the product - targeted at the parents who wanted to monitor the progress of their young readers - would necessarily continue to be browser based, although it might also be delivered as an app on different platforms.

Would it make sense to anticipate these developments and place greater emphasis on the expected "state of the art" in a few years? The danger of doing so would be the resulting loss of potential current revenue and the loss of focus. The danger of failing to do so is that browser-based books might rapidly be perceived as outdated.

\section{Business Model}

Smith's long term goal was to turn IMapBooks into a viable business. Deciding what that business would look like was not easy. There were a number of possibilities that he was considering:

- Subscription. Modeled after services like Netflix, users would pay a monthly fee to access the website containing the collection of IMapBooks and the associated tools for monitoring the progress of readers. To succeed, this particular model would require that a substantial number and variety of books be available.

- Per Book. Modeled after serviced like iTunes and Amazon. Access to the site-and monitoring tools - could be free, with customers purchasing lifetime or limited access to individual books.

- Sell Authoring System. Modeled after development tools such as Adobe Flash or Microsoft .NET. The company could sell the tools authors need to create their own interactive books. For this to strategy to succeed, a robust external market for IMapBooks would need to exist (in order to motivate potential authors to purchase the software).

It would also be possible to create hybrid models (e.g., a subscription fee combined with a per book price for premium works, similar to videos on Amazon Prime.) If sufficiently strong communities developed around the product, it might also be possible to acquire revenue through advertising on the company's portals.

\section{Building Communities}

Another area requiring decisions involved the development of communities. There were two obvious communities: customers (e.g., young readers and their parents) and content creators (e.g., authors and game developers). In addition, there might or might not be third community: programmers involved in engine development.

With respect to the customer community, ensuring a suitable initial target was critical. As noted earlier, Smith and Caris had quickly gravitated towards the home school market, since their purchasing decision was far more streamlined than that of schools and school districts. On the other hand, home schoolers were far from uniform in their values and needs (e.g., religion-based vs. special needs based) and were often outspoken in their opposition to traditional public education. They would also likely to demand a very different collection of content, e.g., an emphasis on religious works, than would mainstream educators. How could the company engage such an individualistic group? And, in doing so, could they avoid antagonizing mainstream educators who might also - eventually — be potential customers?

In order for the company to succeed, it would need to acquire content rapidly. This could potentially entail building a community of two different types of author. The first group would consist of traditional authors who would write the text. The second group would compose the games to be embedded in the 
text, using the set of interactions provided by IMapBooks. While the two groups might overlap, in some situations they would be entirely independent. For example, a large collection of classic works (e.g., Daniel Defoe's "Robinson Crusoe") were in the public domain, meaning that they could be used without any royalty or licensing fee. By incorporating games, a new copyrighted work that could be sold as an IMapBook would be created. By definition, however, such works would be "old", as copyright protection on works currently extends to the lifetime of the author plus 70 years.

If IMapBooks were to succeed as a commercial entity, it would need to entice both text authors and game composers to create and submit content. What incentives could be provided to encourage this? Traditional publishers used royalties to attract authors. For that to be workable, however, IMapBooks would probably need to adopt a business model built upon per-book revenue. It was also possible to hire authors on a "work-for-hire" basis that allowed the hiring company to assume the copyright. This would require capital, but then would permit other business models - such as subscription-based pricing - to be considered.

A final possible community might consist of software developers. This would be an alternative to keeping all technical development in-house. Were such a community to be established, the programmers would develop new types of interactions and would advance the reading and authoring engines. For such a community to succeed, however, the existing technology would probably need to be made open sourcemeaning that competitors in the marketplace could emerge using the very tools that Smith and Drobisz had spent years developing. On the other hand, if a strong programmer community developed around the project, it could evolve and adapt to changing eBook technologies far more rapidly than would be possible for a small in-house team.

\section{Acquiring Capital}

It was becoming clear to Smith that a number of these decisions would be much easier if the company had access to additional capital. For example, with outside funding he could acquire additional key personnel, including:

- A literacy expert

- A marketing person

- Authors

- Another programmer

With additional funding, it would also be much easier to develop a highly professional website to showcase the product to its greatest effect. It would even be possible, he thought, to generate some sales revenue.

Smith had been cautioned, however, that attracting investors would be no easy matter. Did he want to devote his time to that activity, or would that be premature? If he did pursue that path, what would he need to have in place in order to succeed?

\section{Broad Objectives}

Beyond these specific decisions, Smith faced a broader question of priorities. It was challenging being a professor and trying to start a business at the same time. This balancing act was made even more complex by the fact that IMapBooks itself had two objectives: a research objective-determining how incorporating games into a book could enhance learning - and a commercial objective. The research objective was ongoing, as Smith had just recently received funding from the National Science Foundation for a project that involved the IMapBooks technologies and both Drobisz and Caris were also involved in or contem- 
plating research related to the project. Indeed, from a research perspective, the product had already proven successful.

Would it be better to forgo commercial development of the product altogether? That was not an easy question to answer for two reasons. First, Smith felt the time was nearly perfect for the introduction of this type of product into the marketplace. Miss a window of opportunity and the opportunity is gone forever. Second, the success of the research project would be hollow if it did not translate into something that was actually be used by parents and educators. Academia was full of bright ideas that never ended up having any impact because there was no follow through. Did he want IMapBooks to become one of these?

Over the past few weeks, these decisions had gained in urgency. Smith's employer, USF, was investing in acquiring a patent for IMapBooks. In return for these efforts, they were pressing Smith to pay licensing fees. While the initial fees being proposed were not excessive - on the order of $\$ 1000$ - they would represent an out-of-pocket expense to Smith personally. Before paying, he needed to decide if and how the commercial side of the project was going to move forward. 


\section{Acknowledgements}

This case study is based upon work supported by the National Science Foundation under Grant No. 1043919.

\section{Biographies}

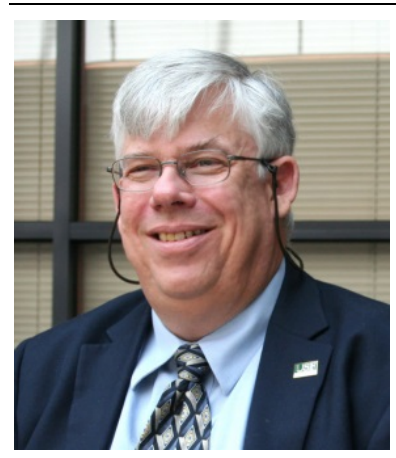

Grandon Gill is a Professor in the Information Systems and Decision Sciences department at the University of South Florida. He holds a doctorate in Management Information Systems from Harvard Business School, where he also received his M.B.A. His principal research areas are the impacts of complexity on decision-making, the diffusion of academic research findings and applying the case method to STEM education. He is currently Editor-inChief of Informing Science: The International Journal of an Emerging Transdiscipline and an Editor of the Journal of IT Education. He is the founding editor of two discussion case repositories: Journal of IT Education: Discussion Cases and Informing Faculty.

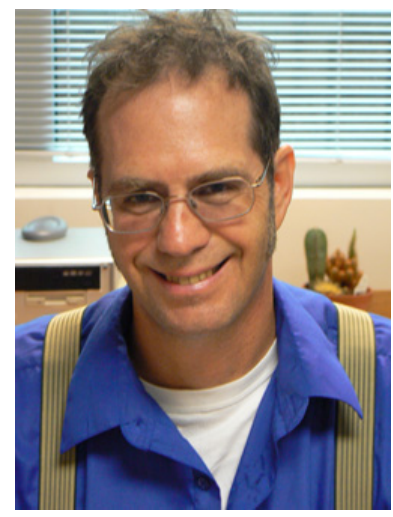

Glenn Smith is an Associate Professor in the Instructional Technology Program, Department of Secondary Education, College of Education at the University of South Florida. Glenn has a Ph.D. in Educational Media \& Computers, and masters and bachelor degrees in Computer Science. He has worked as a computer programmer: a) in Hollywood, California developing computer graphics software for creating television commercials and opening segments for television shows, such as Steven Spielberg's Amazing Stories, b) for Boeing Computer Services, and c) for Microsoft Corporation. 


\section{Exhibit 1: Reasons for Home Schooling}

Figure 2. Percentage and confidence interval estimates of homeschooled students, ages 5 through 17 with a grade equivalent of kingergarten through 12th grade, whose parents reported various reasons for homeschooling: 2003 and 2007

Reasons for homeschooling

A concern about the 2003

school environment 2007

A desire to provide religious 2003

or moral instruction 2007

A dissatisfaction with academic 2003 instruction at other schools 2007

Nontraditional approach 2007 to child's education only

Ollier ieusuis 2003

Child has special needs ${ }^{3} 2003$

Child has a physical or mental health problem

2003 2007

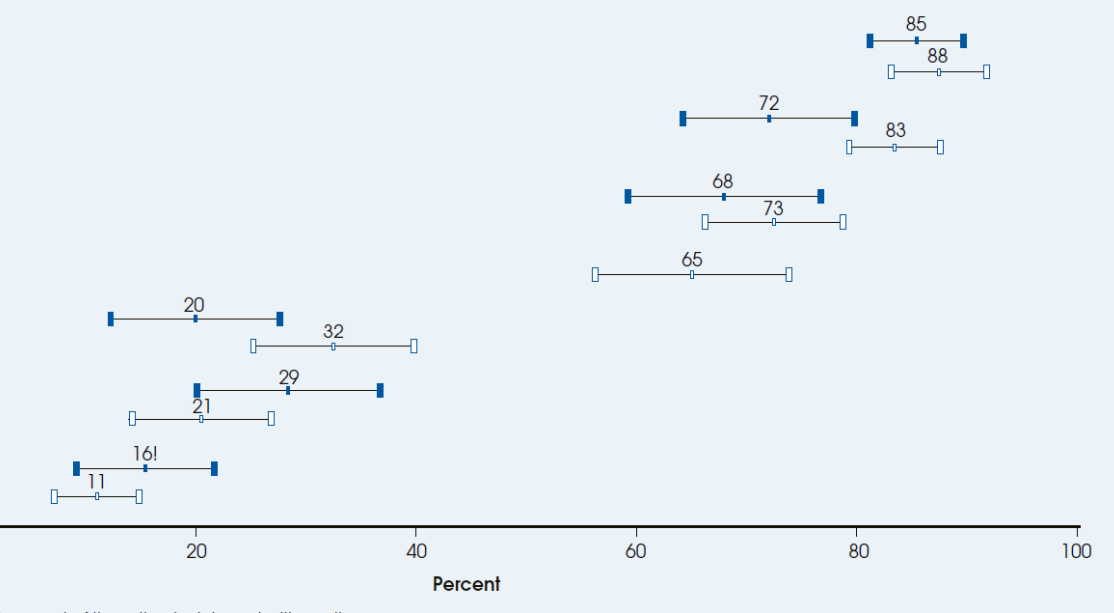

! The standard error for this estimate is greater than 30 percent of the estimate. Interpret with caution.

1 Includes reasons such as safety, drugs, or negative peer pressure.
2 Other reasons parents gave for homeschooling include family time, finances, travel, and distance.

Special needs are needs other than a physical or mental health problem that the parent feels the school cannot or will not meet.

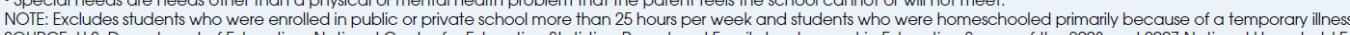

.

Source: U.S. Department of Education, NCES 2009-030 


\section{Exhibit 2: Genesis of IMapBooks}

The genesis of IMapBooks was Dr. Glenn Smith's musings about the nature of the experience of reading novels versus watching movies or TV shows or playing computer games. To many avid readers, including Dr. Smith, the experience of reading a novel is more powerful than watching movies.

Watching a movie is constrained in time to around two hours. Reading a book can go on for weeks, allowing time for a slow burn that totally permeates the reader's subconscious, so that they are walking, living, and breathing a book for weeks. TV shows go on for months or years, but the reader's imaginative participation encourages this subconscious slow burn.

Films and TV shows are enthralling in their immediate delivery of visual and audio details, which the filmmaker realizes for the consumer. However, in reading novels and other text narratives the details are largely left to the imagination of the reader. The reader creates the faces, the body movements, the pitch of the voice of characters, and a myriad of other details of the story, as well as basic story details, in their imaginations. This imaginative participation seems to lead to a greater involvement and is the very core of the magic of the reading experience.

Dr. Smith's research interests in spatial skills (the ability to think in shapes) played an important role in the genesis of IMapBooks. For 12 years Dr. Smith researched how interactive computer programs can improve learning of spatial skills. For example in one of his studies, he demonstrated that pre-service teachers who trained with interactively dragging and rotating shapes, such as triangles, improved their visualization of sequences of such transformations.

The shift in his research from spatial abilities to computer supported reading stemmed from his recreational reading interests. At one point, Dr. Smith was reading military history and found it difficult to visualize troop movements on a battle terrain. Maps helped a little, but were too static. Dr. Smith found it almost impossible to visualize a sequence of troop movements on battlefield. He wondered if it were possible to create an interactive book that helped readers visualize spatially challenging events.

Two major events then crystallized the creation of IMapBooks. The first was Dr. Smith's discovery of a relatively recent body of research (that took off in the 1990s) on the psychology of how readers experience and visualize text narratives. This new area of research provided experimental evidence that readers create mental models of stories they read, and they update their mental models of the story, after reading each sentence, to reflect changes in the story. The mental model readers create is actually called a "situation model," since it models the specific situation in the story. It turns out that readers' situation models have five dimensions: (1) protagonist, which characters are in the current scene and which characters enter and exit the stage (e.g., Armando walked out of the door of Maria's apartment in a glow of alcohol and a buzz of conversation, never to be heard from again.), (2) intentional, the goals of characters and how those goals change over time, for example a sub-goal, completed in service of a larger over-arching goal, gives way to the next sub-goal (e.g., Nadine, a skater full of purple bruises and an aspiration to an Olympic gold medal, learned to perform a reasonable double axel jump, and immediately decided to attempt her first triple-axel without the protective ropes), (3) causal, how one event in the story causes the storyline to shift (e.g., the hurricane flooded Jane's ground floor apartment, so she reluctantly, and definitely temporarily, moved into the second bedroom of the apartment of the dangerously handsome man on the fifth floor), (4) temporal, flashbacks or flash forwards in time (e.g., the scar on John's thumb reminded him of his last great fight with Esmerelda, when she..), and (5) spatial, the spatial configuration of the set- 
ting, where characters and key objects are located in the setting, and where characters and key objects move in the setting (e.g., when detective Ronson returned to the dining room, he could have sworn that the wine glass had been next to the body on the floor, not in its current location washed spotless in the kitchen sink.)

The research on situation models was a revelation for Dr. Smith, as it provided a scientific explanation for his magical experience of reading a great book. He voraciously read every research paper he could get on situation models. The situation model research said unequivocally that the spatial dimension was the most challenging for readers, even experienced, skilled readers. This validated Dr. Smith's experience about the challenge of visualizing troop movements while reading books on military history. He resolved right then and there to research how computer technology could be used to improve readers' comprehension of spatial aspects of text narratives.

The second major event was when a colleague of showed Dr. Smith a pentop computer. Dr. Smith was amazed to see how a pen, containing a tiny computer, could interact with a hardcopy paper. For example, you tapped the pen on a map and a synthesized voice told what historical event happened at that location. Dr. Smith saw this as means to create an interactive book that supported readers' visualization of spatial aspects of situation models, for instance battlefield movements, with computer games.

Dr. Smith wanted people to read and comprehend pages of text with spatial details, and then to engage in a game that supported and challenged their understanding of the spatial details from that story. Dr. Smith wanted the games to help readers comprehend and visualize the spatial content in books, but also to be challenged and held accountable for the spatial details in the stories. Dr. Smith saw accountability as a major ingredient in computer games. For instance, in a 3D first person "shoot' em up" game set in a warehouse space, if the player can't get handle on the spatial arrangement of the setting, they were made accountable with a virtual death. Dr. Smith obtained 25 free pentop computers from a company, got access their programming kernel, purchased an embedded programming language compiler, rounded up some graduate students with programming skills and created some prototype books with games. 


\section{Exhibit 3: Screen captures from an IMapBook}

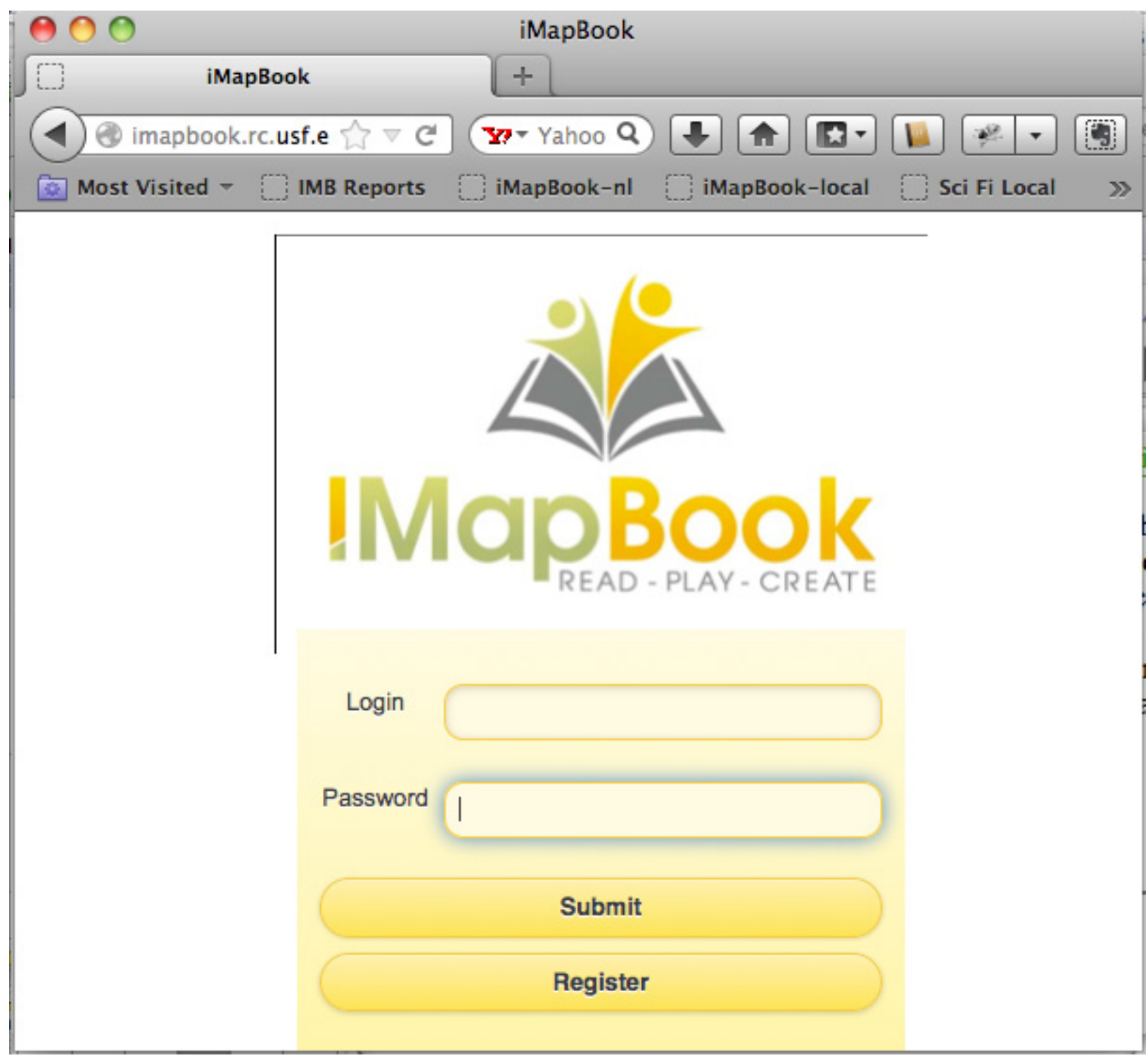

Login screen for the IMapBook eReader 


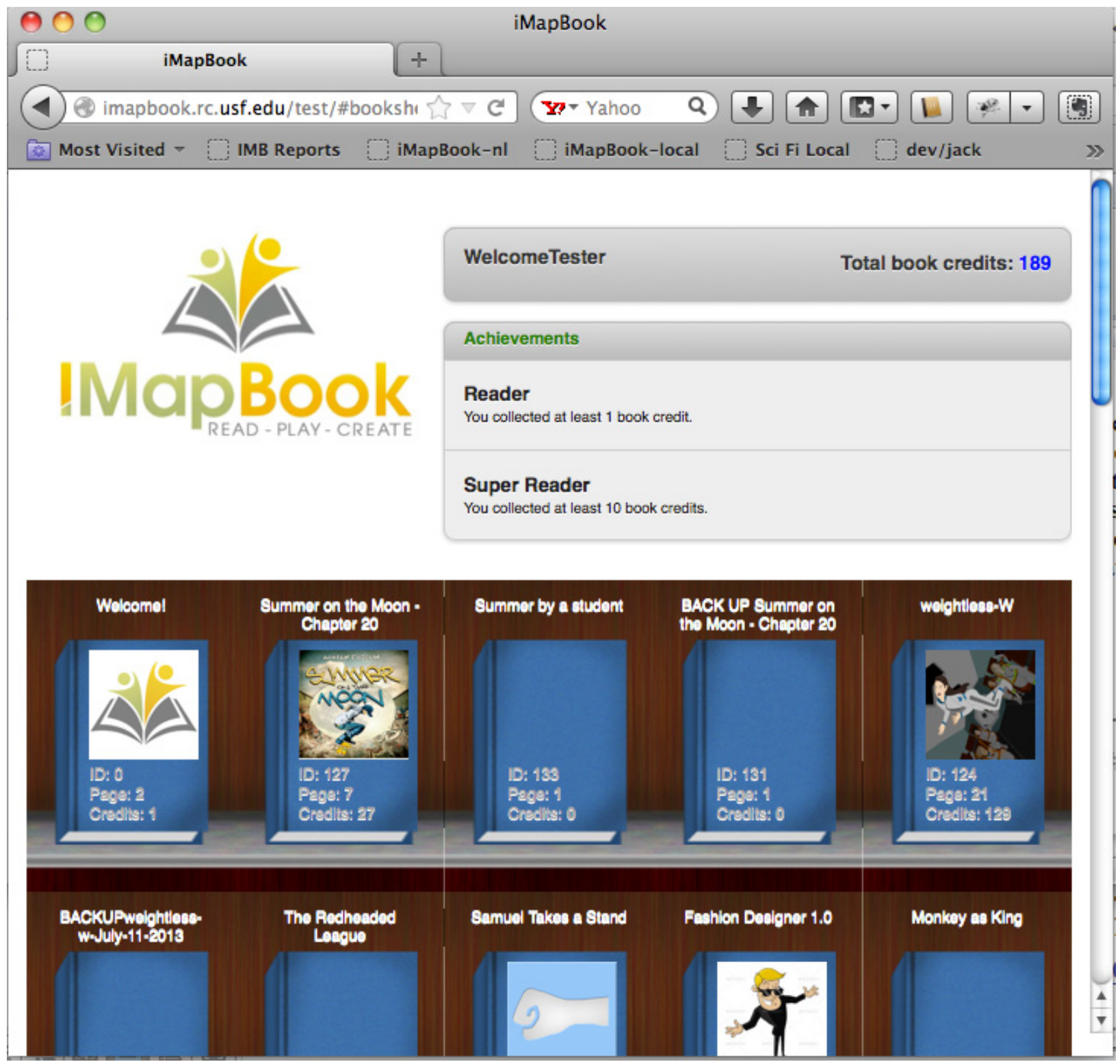

A bookcase in the IMapBook eReader 


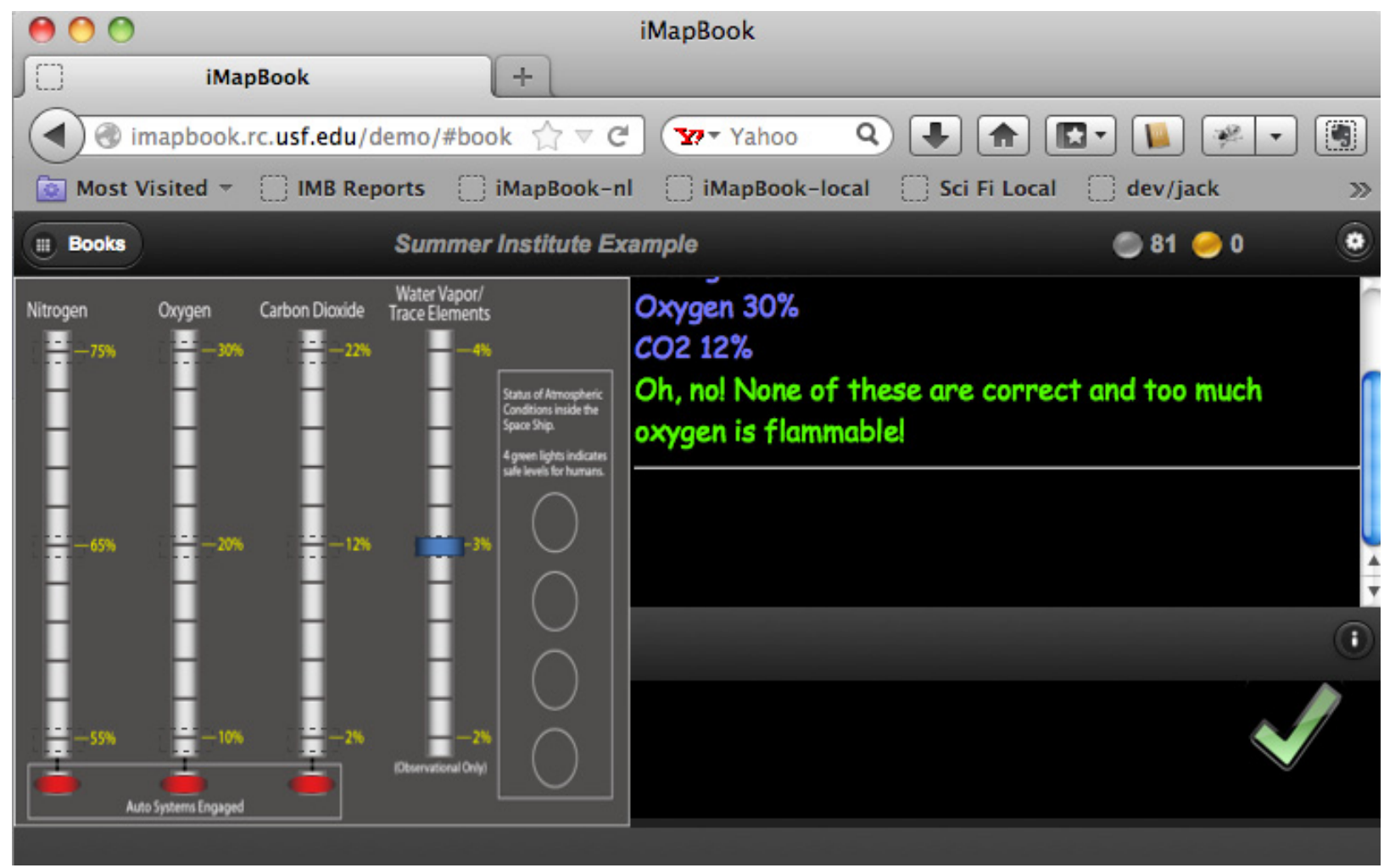

A drag and drop game in an IMapBook: the goal is to set the environmental controls in the spacecraft for human survival 


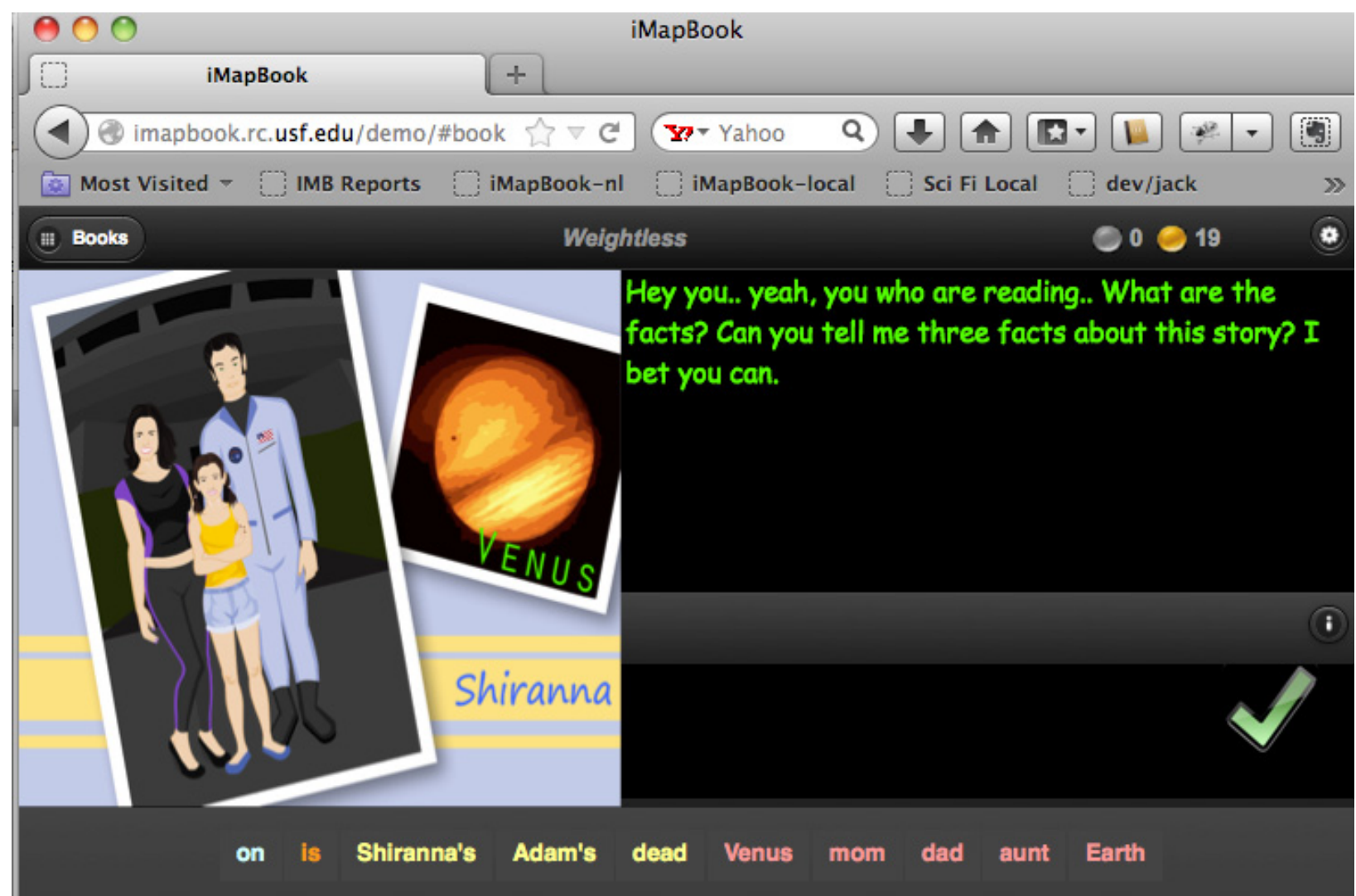

A lexicon-based inference game in an IMapBook: the goal to click on the words to form a sentence that corresponds to a valid inference from the preceding chapter of text. 


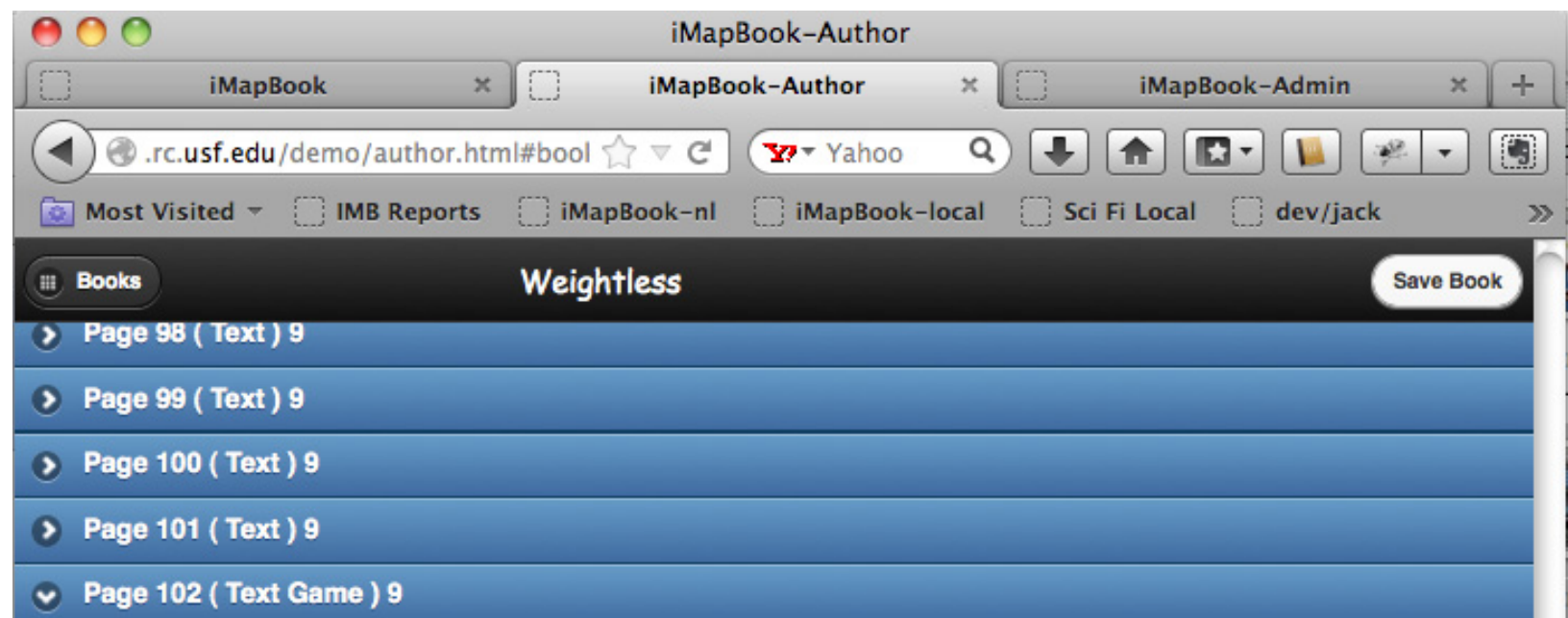

Chapter Label

9
Hide Progress

No
State Image

Gauges_start.png
State Sound

Incoming_weapon_alarm_for_scle...
Minimum Required Score

0

State Text

\section{Adjust the guages so that the mixture of air in the cabin is safe for humans.}

Inside the authoring system that non-technical personnel can use to create IMapBooks and games in IMapBooks 


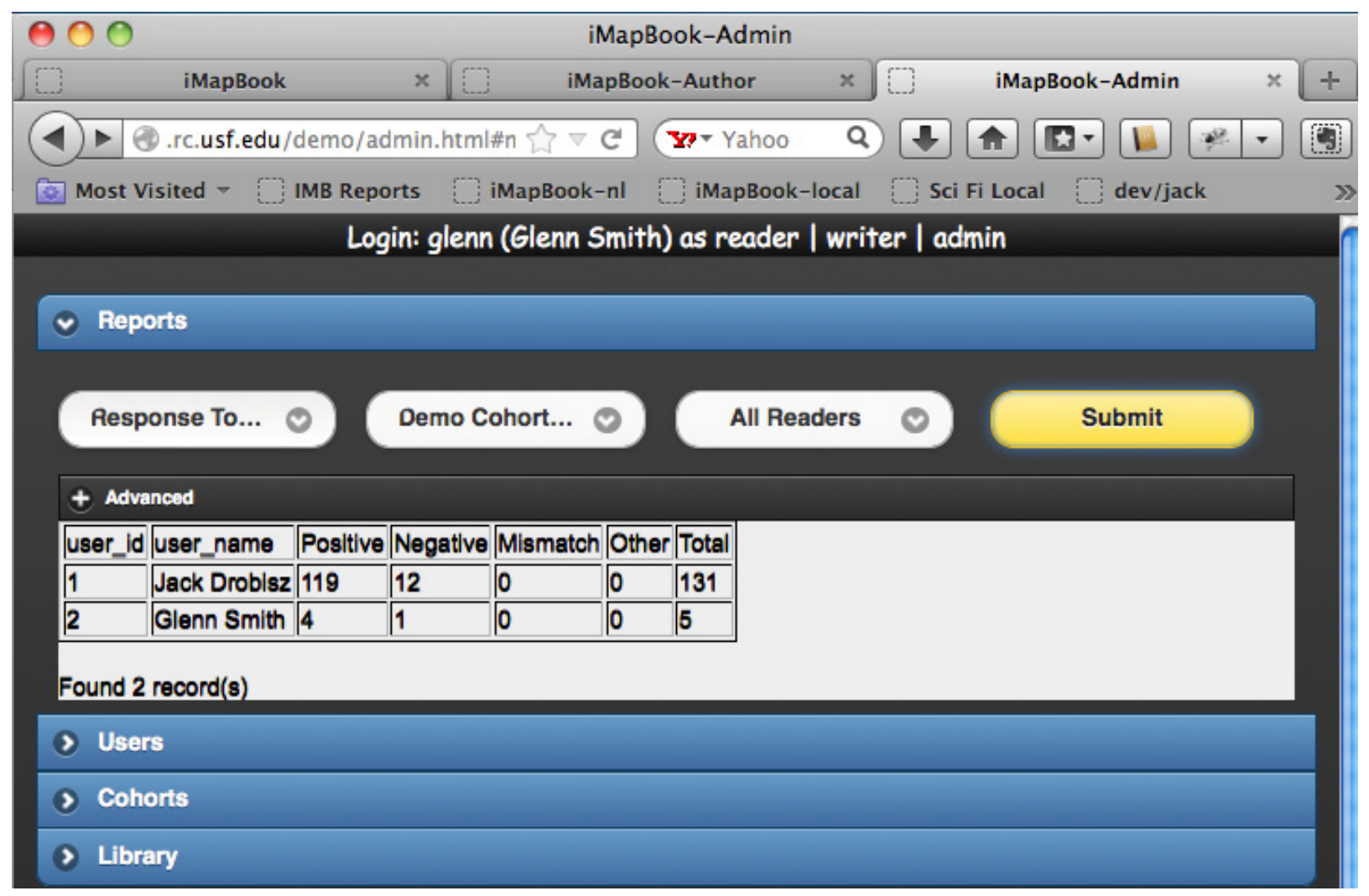

The administrative system: A summary report of user activity 


\section{Exhibit 4: Research Findings from IMapBook Studies}

The iMapBook has now conducted more than eight studies in the United States, one study in China and one study in the Netherlands. Roughly the studies can be divided up into two categories: (1) experimental studies comparing the effectiveness of the IMapBooks approach with other more traditional approaches, and (2) formative evaluations of IMapBooks with the intended target audience, sixth graders.

In terms of the experimental studies investigating the effectiveness of the IMapBooks, one was conducted in the United States with fifth graders. Fifth graders comprehended and retained spatial details in stories (such as configuration of the story settings, and location of objects and character movement within those setting) better with IMapBooks (with computer games) than with equivalent hardcopy books with maps (but not computer games). Fifth graders also had a higher opinion of the very same stories when they read them in IMapBook format versus in a more traditional book form. In another study conducted in China with a very different audience, college students studying English as a Foreign Language (EFF), Chinese EFL students learned more English vocabulary with IMapBooks (with computer games), than they did with their usual vocabulary study method (hardcopy lists of words and definitions, stories with the words and multiple choice questions). The data in the study in the Netherlands, with sixth graders in 25 schools, is yet to be analyzed.

The formative evaluations of iMapBooks have typically been conducted with sixth grade students in United States, using either iPads or desktop PCs. Sixth graders in these formative evaluations, almost to a person reacted enthusiastically to IMapBooks. They seemed to love the idea of reading of text narratives and then playing computer games related to that narrative. Some students even suggested that all books should be IMapBooks. However, students also had many suggestions for improving IMapBooks including: more games for given amount of text (when the ratio of words to games was 3,000 words per game), and later fewer games for given amount of text (when there were 1,000 words per game). Many students suggested making the games more game-like. 